\title{
Ionic liquids as coagents for sulfur vulcanization of butadiene-styrene elastomer filled with carbon black
}

\author{
Magdalena Maciejewska $^{1}$ (D) Marian Zaborski ${ }^{1}$
}

Received: 4 July 2017 / Revised: 5 January 2018/Accepted: 23 January 2018/

Published online: 31 January 2018

(C) The Author(s) 2018. This article is an open access publication

\begin{abstract}
The aim of this work was to study the activity of several alkylimidazolium salts of bis(trifluoromethylsulfonyl)imides to obtain a very fast vulcanization of the butadiene-styrene (SBR) elastomer. Ionic liquids (ILs) such as alkylimidazolium salts with ethyl-, propyl-, butyl-, hexyl-, decyl-, dodecyl-, and hexadecyl chains in the cation together with nanosized zinc oxide are used to develop elastomer composites with very short vulcanization time and a reduced amount of vulcanization activator. In this article, we discuss the effect of the ILs with respect to the length of alkyl chain in their cation on the vulcanization kinetics of rubber compounds. The influence of ILs on the crosslink density as well as the mechanical properties of the vulcanizates and their resistance to thermo-oxidative and UV aging were also studied. ILs resulted in a shortened optimal vulcanization time and reduced the onset vulcanization temperature compared to zinc oxide containing rubber compound. This is very important from a technological point of view. A considerable increase in the crosslink density of vulcanizates was also observed.
\end{abstract}

\section{Introduction}

ILs are defined as organic salts with melting points below $100{ }^{\circ} \mathrm{C}$ [1], which consist of organic cation and organic or inorganic anion. The large size and conformational flexibility of the ILs ions lead to small lattice enthalpies and large entropy changes $[2,3]$. Therefore, the liquid state of ILs is thermodynamically favorable. The most frequently used IL cations are alkylammonium, dialkylimidazolium and $N$ -

Magdalena Maciejewska

magdalena.maciejewska@p.lodz.pl

1 Institute of Polymer and Dye Technology, Lodz University of Technology, Stefanowskiego 12/16, 90-924 Lodz, Poland 
alkylpyridinium [4]. The anions used in ILs range from inorganic anions such as halides, tetrafluoroborates, hexafluorophosphates to large organic anions such as methane sulfonate and bis(trifluoromethylsulfonyl)imides [5, 6]. Owing to their unique properties such as thermal, chemical, and electrochemical stability, low vapor pressure, and high ionic conductivity, ILs have attracted much attention for applications in polymer science $[1,7,8]$, particularly toward developing conducting polymer composites. ILs have excellent ionic conductivity up to their decomposition temperature, which enables them to play an important role in electrolyte matrices $[6,9,10]$. Recently, ILs have been widely used to improve the degree of dispersion of nanoparticles in polymers, particularly in elastomers [11-13]. For example, 1-allyl-3-methylimidazolium chloride (AMICl) was applied to improve the dispersion of carbon black particles in elastomers. Attractive interactions between the carbon black surface and $\mathrm{AMICl}$ have been demonstrated, which resulted from the interaction of $\pi$-electrons of graphitic structures at the carbon black surface with the cations of $\mathrm{AMICl}$ [13]. ILs have also been reported to improve the dispersion of silica and clays [14, 15]. For example, 1-methylimidazolium methacrylate (MimMa) was used to modify the silica surface to increase the interfacial interactions between filler and SBR. Hydrogen bonding between silica particles and the ionic unit of MimMa were confirmed [11]. Moreover, the graft copolymerization of MimMa onto elastomer chains during the vulcanization process was responsible for the reactivity of ionic liquid towards SBR.

ILs have been commonly applied to enhance the interactions between polymers and carbon nanotubes. For example, 1-butyl-3-methylimidazolium bis(trifluoromethylsulfonyl)imide (BmiTFSI) was used to develop conducting composite of multi-walled carbon nanotubes (MWCNTs) and polychloroprene rubber $[12,16]$. The cation- $\pi$ interactions between the BmiTFSI and tubes resulted in uniform dispersion of MWCNTs and the formation of their percolating network, which significantly increased the conductivity of the rubber composite. Similar results were achieved for a blend of carbon nanotubes in a solution-SBR and polybutadiene rubber [17]. The best activity was exhibited by $\mathrm{AMICl}$ - the ionic liquid with a double bond in the cation. It was suggested that the double bond in the ionic liquid molecules was chemically linked by sulfur bridges with double bonds of the diene rubber. Moreover, in the presence of $\mathrm{AMICl}$, the nanotubes strongly adhered to the rubber phase and formed a special type of bound rubber aggregation.

The development of an intrinsically self-healable material based on 1-butyl imidazole (BIM)-modified bromobutyl rubber (BIIR)/natural rubber (NR) blends filled with carbon nanotubes (CNTs) was also reported [18]. The use of BIM as physical crosslinker for the BIIR phase allowed to obtain the non-covalent bondings in the blend composites, which were responsible for their self-healing properties.

Tang et al. [19] used octadecyltriphenylphosphonium iodide IL as a novel catalyst for the silanization reaction between silica and bis(3-triethoxysilylpropyl)tetrasulfide (TESPT) in the silica-filled SBR elastomer. IL reacted with silanol groups on the silica surface to yield more nucleophilic silanolate anions, which promoted the condensation reaction with ethoxy groups of TESPT and consequently increased the extent of silanization. As a result, the dispersion of silica in the SBR and the interfacial interaction between silica and rubber chains were improved. 
Behera et al. [20] fabricated a novel IL-crosslinked flexible polyurethane elastomer using one-pot polymerization method. Tris(2-hydroxyethyl)methylammonium methylsulfate was used as crosslinker. As a result a highly flexible and tough elastomer material was achieved with much lower glass transition temperature than the linear thermoplastic polyurethane elastomer (TPU). Moreover, ILcrosslinked polyurethane elastomer exhibited significantly higher tensile strength, elongation at break and lower hardness, as compared to conventional TPU.

In the past few years, ILs have also been employed as solvents for various types of polymerization [21-23], to dissolve polymers (cellulose [24], silk fibroin [25], starch [26]) or as plasticizers for different polymers [27, 28].

Considering the wide applications of ILs in polymer science and also in elastomer composites, in this work, we intended to apply alkylimidazolium salts of bis(trifluoromethylsulfonyl)imides to improve the dispersion of curatives and carbon black particles in the SBR elastomer. Moreover, because of the catalytic activity during interfacial reactions $[1,5]$, ILs are expected to act as coagents in sulfur vulcanization of SBR, increasing the rate and efficiency of curing. According to the commonly reported vulcanization mechanism, accelerator particles, sulfur and fatty acids diffuse through the elastomer matrix and are adsorbed onto the surface of the vulcanization activator (zinc oxide), forming intermediate reactive complexes and the active sulfurating agent, which takes part in further crosslinking reactions. Due to the limited solubility of these complexes in the rubber, it is assumed that crosslinking reactions occur at the interface between the curatives and the rubber chains and can be catalyzed by the phase transfer catalysts [29]. As a result, the improvement in the crosslink density and mechanical properties of vulcanizates as well as the reduction of vulcanization time and temperature could be achieved.

\section{Experimental}

\section{Materials}

SBR elastomer (KER 1500) containing 22-25 wt\% styrene was obtained from Synthos S.A., Oswiecim (Poland). Its Mooney viscosity was ML1+4 $\left(100{ }^{\circ} \mathrm{C}\right)$ : 46-54. It was vulcanized with sulfur (Siarkopol, Tarnobrzeg, Poland) with microsized zinc oxide as the standard activator (M-ZnO, Huta Bedzin, Poland). 2-mercaptobenzothiazole (Sigma-Aldrich, Schnelldorf, Germany) and N-cyclohexyl-2-benzothiazolesulfenamide (Alfa Aesar, Lancashire, United Kingdom) were applied as accelerators. To reduce the amount of zinc ions in the rubber compounds, nanosized zinc oxide $(\mathrm{N}-\mathrm{ZnO})$ with a specific surface area of $42.5 \mathrm{~m}^{2} / \mathrm{g}$ and an average particle size of $234 \mathrm{~nm}$ (Qinetiq Nanomaterials Limited, Hampshire, United Kingdom) was used as an alternative to standard microsized $\mathrm{ZnO}$. Ionic liquids were applied as vulcanization coagents to increase the efficiency and reduce the time of vulcanization. ILs given in Table 1 were provided by IoLiTec Ionic Liquids Technologies GmbH, Heilbronn, Germany. Carbon black N550 was used as a filler. 
Table 1 ILs used as coagents of vulcanization

\begin{tabular}{lc}
\hline Ionic liquid & Symbol \\
\hline 1-Ethyl-3-methylimidazolium bis(trifluoromethylsulfonyl)imide & EmiTFSI \\
1-Methyl-3-propylimidazolium bis(trifluoromethylsulfonyl)imide & MpiTFSI \\
1-Butyl-3-methylimidazolium bis(trifluoromethylsulfonyl)imide & BmiTFSI \\
1-Hexyl-3-methylimidazolium bis(trifluoromethylsulfonyl)imide & HmiTFSI \\
1-Decyl-3-methylimidazolium bis(trifluoromethylsulfonyl)imide & DmiTFSI \\
1-Dodecyl-3-methylimidazolium bis(trifluoromethylsulfonyl)imide & DomiTFSI \\
1-Hexadecyl-3-methylimidazolium bis(trifluoromethylsulfonyl)imide & HdmiTFSi \\
\hline
\end{tabular}

\section{Preparation and characterization of rubber compounds}

Rubber compounds with the formulations given in Table 2 were prepared using a laboratory two-roll mill. The samples were cured at $160{ }^{\circ} \mathrm{C}$ until they developed a $90 \%$ increase in torque $(G)$, as measured by a rotational rotorless rheometer D-RPA 3000 (MonTech, Buchen, Germany). The kinetics of rubber compound vulcanization was studied using a DSC1 (Mettler Toledo, Greifensee, Switzerland) analyzer by decreasing the temperature from 25 to $-100{ }^{\circ} \mathrm{C}$ at a rate of $10{ }^{\circ} \mathrm{C} / \mathrm{min}$ and then heating to $250{ }^{\circ} \mathrm{C}$ at the same rate.

The crosslink densities $\left(v_{e}\right)$ of the vulcanizates were determined by their equilibrium swelling in toluene, based on the Flory-Rehner equation [30]. The Huggins parameter of the SBR-solvent interaction $(\chi)$ was calculated from the Eq. (1) [31], where $V_{r}$ is the volume fraction of elastomer in the swollen gel.

$$
\chi=0.37+0.56 V_{r} .
$$

The tensile properties of the vulcanizates were measured according to the ISO-37 standard procedures using a ZWICK 1435 (Zwick, Ulm, Germany) universal machine.

\section{Dynamic-mechanical analysis (DMA)}

DMA measurements were performed in tension mode using a DMA/SDTA861 ${ }^{\mathrm{e}}$ analyzer (Mettler Toledo, Greifensee, Switzerland). Measurements of the dynamic

Table 2 Composition of the SBR-based rubber compounds, phr (parts per hundred of rubber)

\begin{tabular}{llll}
\hline Compound & $\mathrm{R} 1$ & $\mathrm{R} 2$ & $\mathrm{SBR} 1-7$ \\
\hline SBR & 100 & 100 & 100 \\
Sulfur & 2 & 2 & 2 \\
Accelerator (MBT) & 1 & 1 & 1 \\
Accelerator (CBS) & 1 & 1 & 1 \\
$\mathrm{M}-\mathrm{ZnO}$ & 5 & - & - \\
$\mathrm{N}-\mathrm{ZnO}$ & - & 2 & 2 \\
Ionic liquid & - & - & 3 \\
Carbon black & 30 & 30 & 30 \\
\hline
\end{tabular}


moduli were carried out over the temperature range of $-80-50{ }^{\circ} \mathrm{C}$ with a heating rate of $3{ }^{\circ} \mathrm{C} / \mathrm{min}$, a frequency of $1 \mathrm{~Hz}$, and a strain amplitude of $0.05 \%$. The temperature of the elastomer glass transition was determined from the maximum of $\tan \delta=f(T)$ curve, where $\tan \delta$ is the loss factor and $T$ is the measurement temperature.

\section{Thermo-oxidative and UV aging}

The thermo-oxidative aging of the vulcanizates was performed at a temperature of $100{ }^{\circ} \mathrm{C}$ for $240 \mathrm{~h}$. The UV degradation of the vulcanizates was carried out for $120 \mathrm{~h}$ using a UV 2000 (Atlas) machine in two alternating segments: a day segment (irradiation $0.7 \mathrm{~W} / \mathrm{m}^{2}$, temperature $60^{\circ} \mathrm{C}$, time $8 \mathrm{~h}$ ) and a night segment (temperature $50{ }^{\circ} \mathrm{C}$, time $4 \mathrm{~h}$ ).

To estimate the resistance of the material to aging, their mechanical properties and crosslink densities after aging were determined and compared with the values obtained for the vulcanizates before the aging process. The aging factor $(S)$ was calculated as the change in the deformation energy of the samples upon aging (Eq. 2) [32], where TS is the tensile strength of the vulcanizates and EB is the elongation at break:

$$
S=x(\mathrm{TS} \cdot \mathrm{EB})_{\text {afteraging }} /(\mathrm{TS} \cdot \mathrm{EB})_{\text {beforeaging }} .
$$

\section{Scanning electron microscopy (SEM)}

The degree of dispersion of curatives and filler particle in the elastomer matrix was estimated using scanning electron microscopy with a LEO 1530 SEM. The vulcanizates were broken down in liquid nitrogen, and the surfaces of the vulcanizate fractures were examined. Prior to the measurements, the samples were coated with carbon.

\section{Results and discussion}

\section{Dispersion degree of curatives and filler particles in the SBR}

SEM images were taken to estimate the dispersion degree of curatives and filler particles in the elastomer in the presence of ILs (Figs. 1, 2, 3, 4). The degree of dispersion of curatives, especially zinc oxide particles in the elastomer matrix, is very important to the activation of sulfur vulcanization. Homogeneous dispersion provides better contact between particles of the activator and other components of the crosslinking system. It enhances the efficiency of vulcanization.

The curatives and filler particles are not homogeneously dispersed in the elastomer. Microsized agglomerates consisting of nanosized primary particles could be seen in the SEM image (Fig. 1). ILs improved the dispersibility of solids in the SBR, preventing particles of curatives and carbon black from agglomeration 


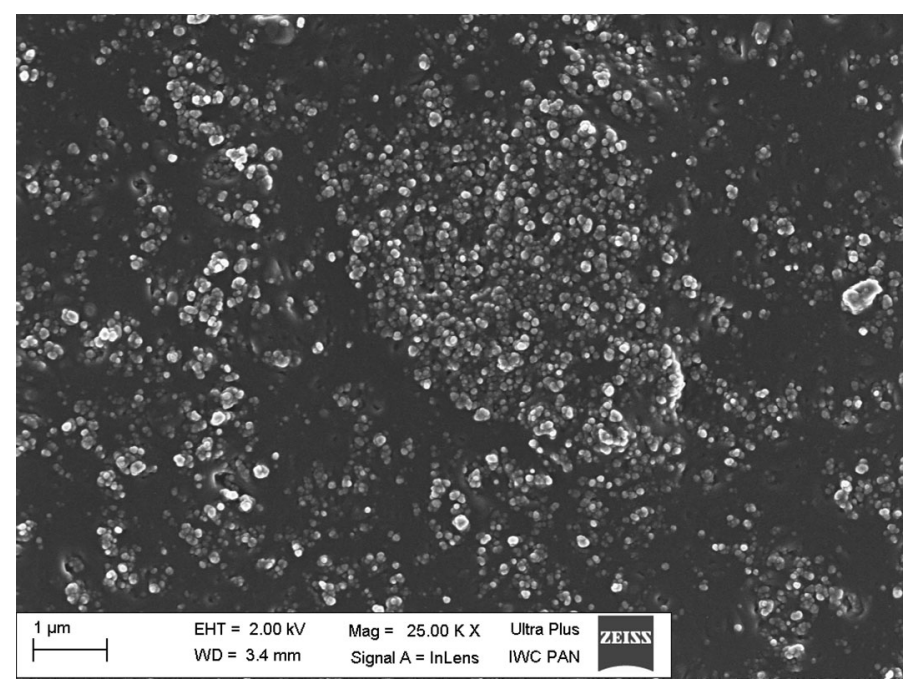

Fig. 1 SEM image of SBR vulcanizate containing N-ZnO without IL (R2)

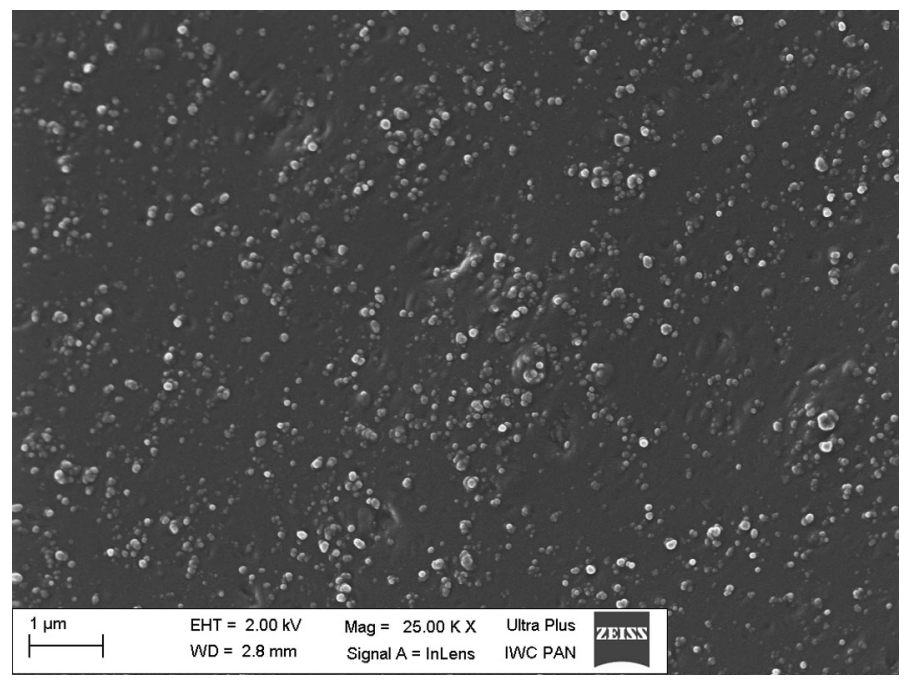

Fig. 2 SEM image of SBR vulcanizate containing N-ZnO and MpiTFSI (SBR2)

(Figs. 2, 3, 4). This could be due to the interactions between functional groups present on the carbon black surface and ionic liquids similar to those observed for BmiTFSI and carbon nanotubes [10].

\section{Curing characteristics and the crosslink density of SBR vulcanizates}

As was confirmed, ILs improved the degree of dispersion of the curative particles in the elastomer matrix. Therefore, they should affect the vulcanization efficiency of 


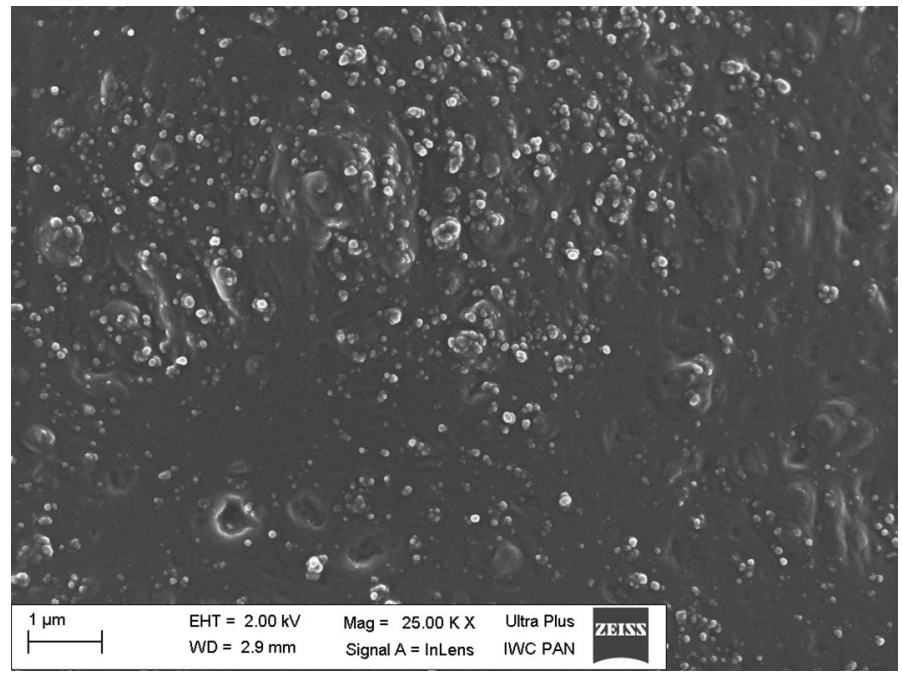

Fig. 3 SEM image of SBR vulcanizate containing N-ZnO and HmiTFSI (SBR4)

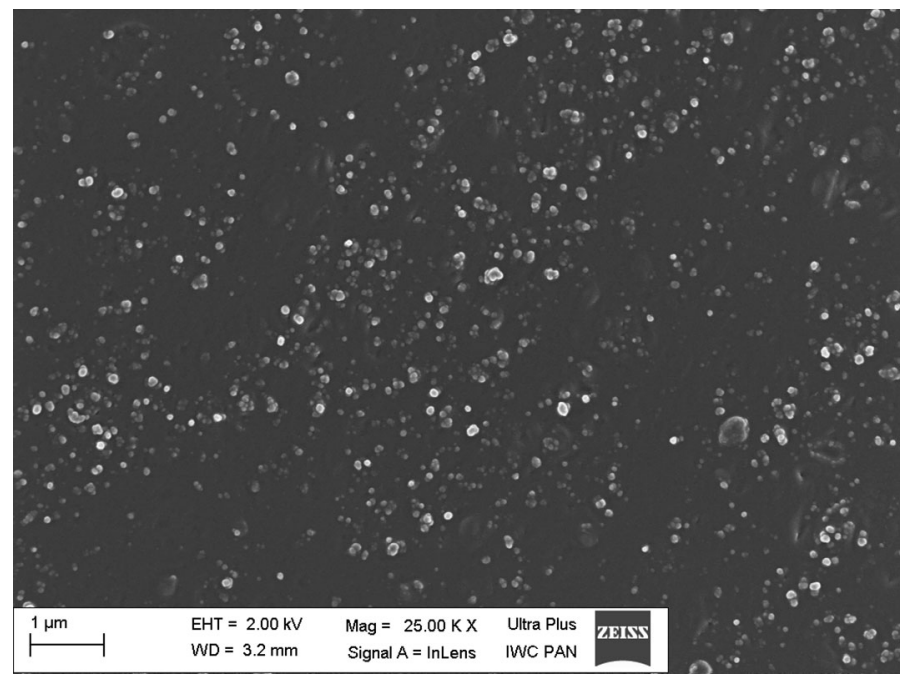

Fig. 4 SEM image of SBR vulcanizate containing N-ZnO and DmiTFSI (SBR5)

SBR compounds. Moreover, ILs are considered to catalyze the interface reactions, whereas crosslinking reactions proceed at the interface between the elastomer and curatives. The influence of the ILs on the vulcanization process was estimated based on rheometer measurements. The cure characteristics of SBR compounds and crosslink densities of vulcanizates are given in Table 3.

The $\mathrm{N}-\mathrm{ZnO}$ used alternatively to $\mathrm{M}-\mathrm{ZnO}$ seems to be very effective in the activation of elastomer vulcanization. Despite its amount in the rubber compound being $60 \%$ lower than that of $\mathrm{M}-\mathrm{ZnO}$, it increased the crosslink density of the 
Table 3 Cure characteristics of SBR compounds and crosslink densities of vulcanizates ( $\Delta G$-increase of

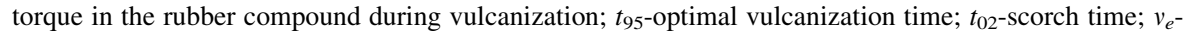
crosslink density of vulcanizate)

\begin{tabular}{llllll}
\hline Rubber compound & Activator & $\Delta G, \mathrm{dNm}$ & $t_{95}, \min$ & $t_{02}, \mathrm{~min}$ & $v_{e} \times 10^{5}, \mathrm{~mole} / \mathrm{cm}^{3}$ \\
\hline R1 & M-ZnO & 16.8 & 20 & 0.7 & 2.22 \\
R2 & N-ZnO & 15.5 & 15 & 1.0 & 3.40 \\
SBR1 & N-ZnO/EmiTFSI & 15.5 & 4 & 0.9 & 4.09 \\
SBR2 & N-ZnO/MpiTFSI & 15.7 & 4 & 0.9 & 4.49 \\
SBR3 & N-ZnO/BmiTFSI & 15.2 & 4 & 0.9 & 4.21 \\
SBR4 & N-ZnO/HmiTFSI & 16.0 & 4 & 0.8 & 4.26 \\
SBR5 & N-ZnO/DmiTFSI & 15.5 & 4 & 0.9 & 4.02 \\
SBR6 & N-ZnO/DomiTFSI & 15.7 & 4 & 0.8 & 4.31 \\
SBR7 & N-ZnO/HdmiTFSI & 15.4 & 4 & 0.9 & 4.63 \\
\hline
\end{tabular}

vulcanizate and allowed the torque to be increased during vulcanization, similar to SBR containing microsized $\mathrm{ZnO}$. It also decreased the vulcanization time of the SBR by $5 \mathrm{~min}$ and had no considerable influence on the scorch time. Applying ILs resulted in a considerably shorter vulcanization time compared to $\mathrm{M}-\mathrm{ZnO}$ or $\mathrm{N}-\mathrm{ZnO}$ systems. Regardless of the type of IL used, the cure time of SBR was 4 min. Moreover, ILs considerably increased the crosslinks density of vulcanizates. This confirms that ILs act as catalysts of interface crosslinking reactions. The improvement of curative dispersion, especially zinc oxide, in the elastomer could also contribute to a reduction of rubber compound vulcanization times and an increase of crosslink density. Moreover, as postulated for stearic acid, ILs can improve the solubility of the active sulfurating agent that is formed during vulcanization process in the elastomer [29]. As a result, the crosslinking rate and degree increase. Generally, a silane coupling agent is used to increase the interaction between the nonpolar elastomer and the highly polar silica used as filler. In this case, ILs can adsorb on the filler surface, as postulated in the literature [11] and increase the interphase interactions between the elastomer and filler. It is known that during vulcanization, accelerators adsorb on the filler's surface, decreasing the efficiency of vulcanization. Therefore, the increase in vulcanization efficiency in the presence of ILs can be attributed not only to the aforementioned factors, such as catalytic activity and the improved curatives dispersibility in the elastomer, but also to the adsorption of ILs on the filler's surface, which reduces the ability to adsorb curatives and water. The length of alkyl chains in the imidazolium cation of ILs had no significant effect on their activity in the crosslinking process. The torque increment $\Delta \mathrm{G}$ during vulcanization of rubber compounds containing ILs as well as the crosslink density of vulcanizates were similar.

In the next step of the study, the influence of ILs on the temperature and enthalpy of vulcanization was determined using DSC analysis. The results for SBR compounds are given in Table 4. 
Table 4 Temperature and enthalpy of SBR vulcanization measured by DSC

\begin{tabular}{llll}
\hline Rubber compound & Activator & $\begin{array}{l}\text { Vulcanization temperature } \\
\text { range, }{ }^{\circ} \mathrm{C}\end{array}$ & $\begin{array}{l}\text { Enthalpy of } \\
\text { vulcanization, J/g }\end{array}$ \\
\hline R1 & $\mathrm{M}-Z n O$ & $169-212$ & 8.0 \\
R2 & $\mathrm{N}-Z n O$ & $158-186$ & 4.1 \\
SBR1 & N-ZnO/EmiTFSI & $144-181$ & 3.8 \\
SBR2 & N-ZnO/MpiTFSI & $148-173$ & 4.1 \\
SBR3 & N-ZnO/BmiTFSI & $145-174$ & 4.3 \\
SBR4 & N-ZnO/HmiTFSI & $144-181$ & 3.6 \\
SBR5 & N-ZnO/DmiTFSI & $149-184$ & 4.4 \\
SBR6 & N-ZnO/DomiTFSI & $148-183$ & 3.6 \\
SBR7 & N-ZnO/HdmiTFSI & $147-176$ & 3.5 \\
\hline
\end{tabular}

The vulcanization of SBR is an exothermic process that proceeds in a temperature range of $169-212{ }^{\circ} \mathrm{C}$, with an enthalpy of $8 \mathrm{~J} / \mathrm{g}$. N-ZnO decreased the vulcanization onset temperature by $11^{\circ} \mathrm{C}$ and the enthalpy of vulcanization by $4 \mathrm{~J} / \mathrm{g}$ compared to rubber compound with microsized activator. It is worth noting that ILs caused a further decrease in the vulcanization onset temperature to the range of $144{ }^{\circ} \mathrm{C}$ (EmiTFSI) and $149{ }^{\circ} \mathrm{C}$ (DmiTFSI). This is important for technological reasons because application of ILs allows the SBR to be cured at temperatures lower than the commonly used $160^{\circ} \mathrm{C}$. ILs did not influence significantly the enthalpy of vulcanization compared to rubber compound containing $\mathrm{N}-\mathrm{ZnO}$. The influence of the ILs structure on the vulcanization temperature or enthalpy was not observed.

\section{Mechanical properties of SBR vulcanizates}

As confirmed by SEM images, applying the ILs allowed a homogeneous dispersion of the curatives and carbon black particles in the elastomer, and therefore we expected improved mechanical properties of the vulcanizates, such as the tensile strength. The mechanical properties of the SBR vulcanizates filled with carbon black were studied under static and dynamic conditions. The results of the tensile tests are presented in Table 5.

The TS of SBR crosslinked with M-ZnO was $20.1 \mathrm{MPa}$, and an EB was approximately $777 \%$. N-ZnO increased the TS of vulcanizate by $2 \mathrm{MPa}$, whereas the EB did not considerably change. ILs caused a considerable increase in the modulus at a $300 \%$ relative elongation of the vulcanizates and reduced the EB by more than $100 \%$. This resulted from the significant increase in the crosslink density of vulcanizates. The lowest EB (about 570\%) was achieved for vulcanizate containing HdmiTFSI, which exhibited the highest crosslink density. Despite the improvement of filler dispersion in the SBR elastomer, ILs had no positive effect on the TS. Only vulcanizate containing DmiTFSI exhibited TS similar to the reference sample with $\mathrm{N}-\mathrm{ZnO}$. Other ILs, especially with long alkyl chains in the imidazolium cation (DomiTFSI, HdmiTFSI), deteriorated the TS of vulcanizates. This effect was 
Table 5 Mechanical properties of SBR vulcanizates $\left(\mathrm{SE}_{300^{-}}\right.$ modulus at a relative elongation of $300 \%$, TS-tensile strength, EB-elongation at break, standard deviation of $\mathrm{SE}_{300} \pm 0.5 \mathrm{MPa}$, $\mathrm{TS} \pm 1.2 \mathrm{MPa}, \mathrm{EB} \pm 40 \%$ )

\begin{tabular}{lllll}
\hline Vulcanizate & Activator & $\mathrm{SE}_{300}, \mathrm{MPa}$ & $\mathrm{TS}, \mathrm{MPa}$ & $\mathrm{EB}, \%$ \\
\hline R1 & M-ZnO & 3.1 & 20.1 & 777 \\
R2 & N-ZnO & 3.4 & 22.4 & 781 \\
SBR1 & N-ZnO/EmiTFSI & 5.7 & 20.2 & 646 \\
SBR2 & N-ZnO/MpiTFSI & 6.2 & 21.0 & 678 \\
SBR3 & N-ZnO/BmiTFSI & 5.6 & 20.1 & 630 \\
SBR4 & N-ZnO/HmiTFSI & 5.3 & 19.0 & 659 \\
SBR5 & N-ZnO/DmiTFSI & 4.9 & 22.6 & 663 \\
SBR6 & N-ZnO/DomiTFSI & 5.1 & 17.6 & 650 \\
SBR7 & N-ZnO/HdmiTFSI & 5.5 & 15.7 & 572 \\
\hline
\end{tabular}

most significant for vulcanizates containing ILs with decyl-, dodecyl-, and hexadecyl- chains in the cation (DmiTGSI, DomiTFSI, HdmiTFSI). However, these values of vulcanizate TS are still acceptable for technological applications of obtained rubber composites.

Dynamic mechanical properties are important for the technological application of rubber products, which very often work in the conditions of variable stress and strain. The influence of ILs on the loss factor $(\tan \delta)$ was determined with DMA. The loss factor is a measure of the material's ability to dampen vibration. In Fig. 5, a plot of $\tan \delta$ as a function of temperature for the vulcanizates containing ILs is presented, and the data are also shown in Table 6.

The maximum of $\tan \delta$ in the DMA curve represents the glass transition temperature $T_{g}$ of SBR, which was approximately $-41.6^{\circ} \mathrm{C}$. Applying N-ZnO and

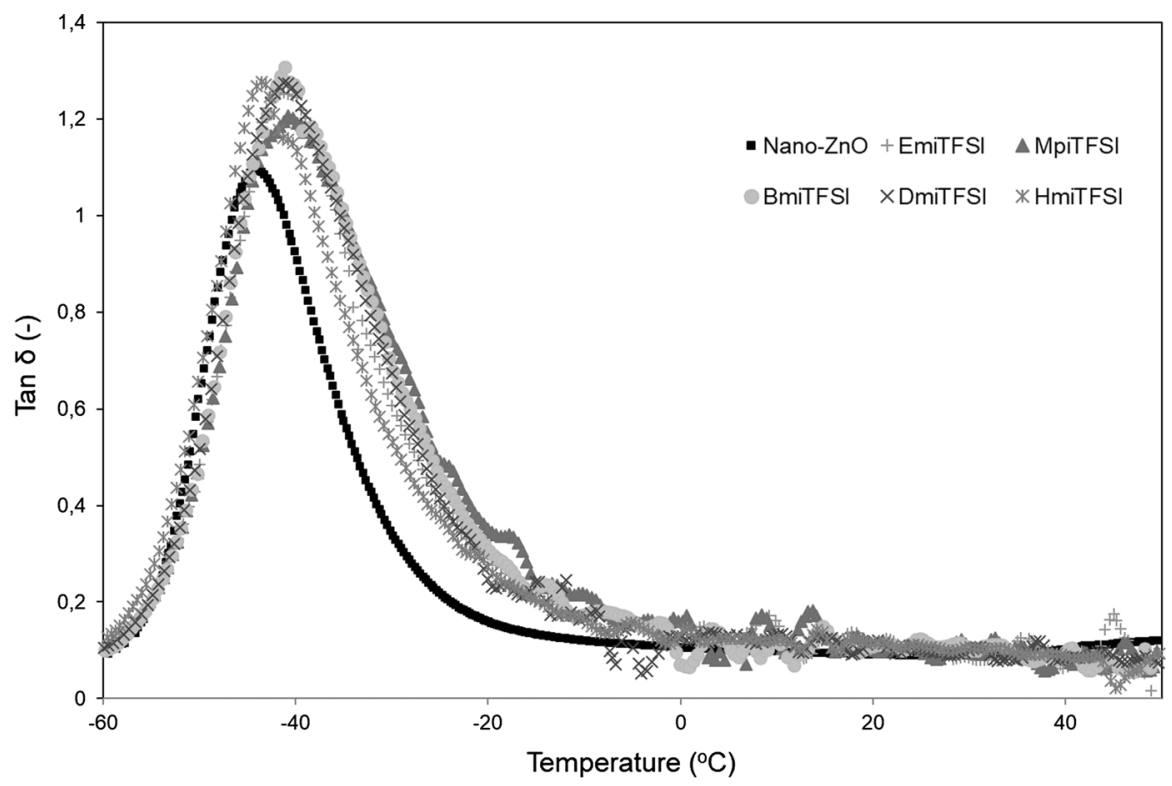

Fig. 5 Loss factor $(\tan \delta)$ versus temperature for SBR vulcanizates 
Table $6 T_{g}$ and loss factor ( $\tan \delta$ ) of SBR vulcanizates (standard deviation of $T_{g} \pm 0.5{ }^{\circ} \mathrm{C}, \tan \delta \pm 0.02$ )

\begin{tabular}{llllll}
\hline Vulcanizate & Activator & $T_{g},{ }^{\circ} \mathrm{C}$ & $\tan \delta$ at $T_{g}$ & $\tan \delta$ at $25{ }^{\circ} \mathrm{C}$ & $\tan \delta$ at $50{ }^{\circ} \mathrm{C}$ \\
\hline R1 & M-ZnO & -41.6 & 1.02 & 0.15 & 0.12 \\
R2 & N-ZnO & -42.9 & 1.08 & 0.12 & 0.09 \\
SBR1 & N-ZnO/EmiTFSI & -42.1 & 1.25 & 0.10 & 0.06 \\
SBR2 & N-ZnO/MpiTFSI & -40.8 & 1.21 & 0.10 & 0.06 \\
SBR3 & N-ZnO/BmiTFSI & -41.1 & 1.31 & 0.12 & 0.06 \\
SBR4 & N-ZnO/HmiTFSI & -42.5 & 1.28 & 0.11 & 0.09 \\
SBR5 & N-ZnO/DmiTFSI & -41.3 & 1.27 & 0.10 & 0.07 \\
\hline
\end{tabular}

ILs had no considerable influence on the $T_{g}$ of elastomer. Regarding the loss factor, ILs increased the value of $\tan \delta$ at $T_{g}$ but had no significant effect on $\tan \delta$ at 25 or $50{ }^{\circ} \mathrm{C}$. Considering the magnitude of the change in the value of the loss factor, it can be concluded that the use of ILs had no significant effect on the vibration damping ability of vulcanizates at usage temperatures. In addition, vulcanizates exhibited stable dynamic properties at the temperatures studied.

\section{Aging resistance of SBR vulcanizates}

Considering technical applications of rubber products based on the SBR, aging resistance is their most important property. Therefore, ILs used to increase the efficiency of sulfur vulcanization of SBR should not deteriorate aging resistance.

The effect of $\mathrm{N}-\mathrm{ZnO}$ and ILs on vulcanizate resistance to UV and thermooxidative aging was examined through the change in their mechanical properties and crosslink density.

In Fig. 6, the change in EB upon aging is given for SBR vulcanizates. The aging process had a considerable impact on the EB of vulcanizates, causing it to decrease by approximately $200-300 \%$ for UV aging and $300-500 \%$ for thermo-oxidative aging. These changes were caused by large increases in the crosslink density of the vulcanizates, especially evident for thermo-oxidative aging (Fig. 7). Owing to the considerable changes in the crosslink density of SBR vulcanizates, the aging process deteriorated their TS. The smallest change in TS was achieved for vulcanizates containing long alkyl chain ILs, such as: HmiTFSI, DomiTFSI and HdmiTFSI (Fig. 8).

To quantitatively estimate the change in the mechanical properties of vulcanizates due to aging, the aging factor S was calculated (Fig. 9) as a measurement of the changes in the sample deformation energy caused by the aging process. Values of the S-factor that are closer to 1 indicate smaller changes in the mechanical properties of the vulcanizates due to the aging process.

The $\mathrm{S}$ factor for vulcanizate containing $\mathrm{M}-\mathrm{ZnO}$ without ILs is 0.51 (UV aging) and 0.38 (thermo-oxidative aging). It can be concluded that the SBR vulcanizates are characterized by a susceptibility to degradation under prolonged exposure to elevated temperatures. The application of $\mathrm{N}-\mathrm{ZnO}$ slightly reduced the aging 


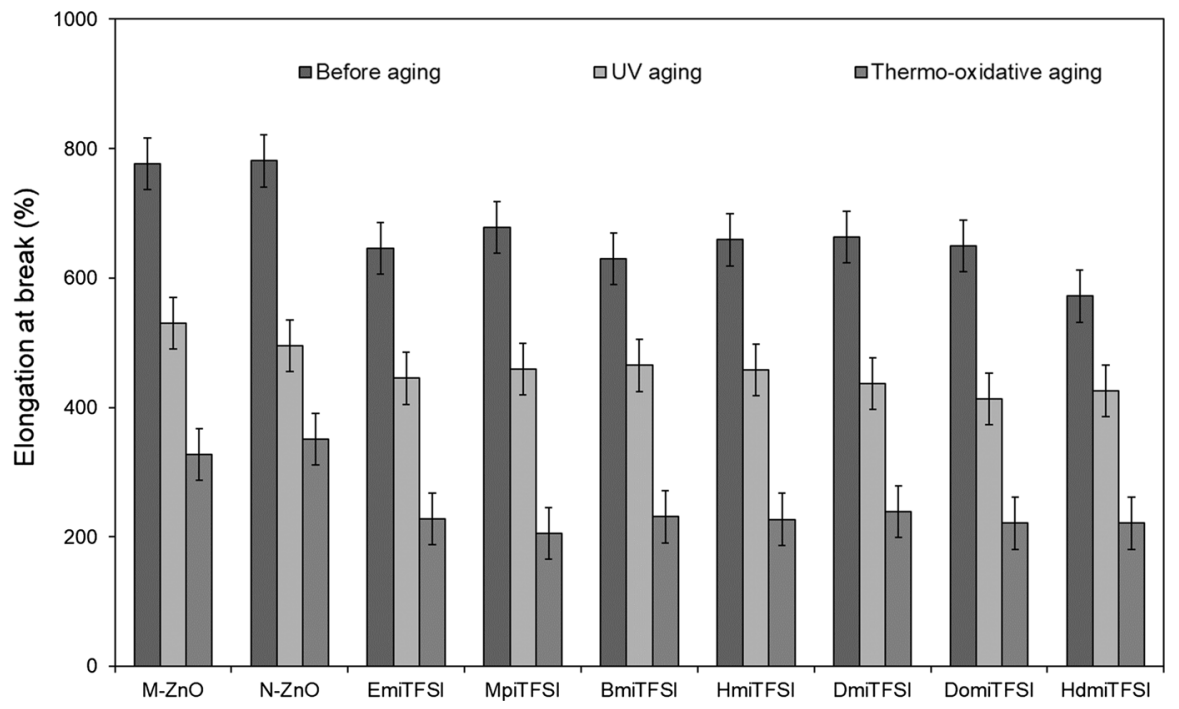

Fig. 6 Elongation at breaks of SBR vulcanizates after aging

resistance of SBR, especially in the case of UV radiation (Fig. 9). This is probably due to the higher ability of $\mathrm{N}-\mathrm{ZnO}$ to absorb UV radiation [33]. ILs improved the SBR resistance to UV aging but did not significantly improve the resistance of SBR to thermo-oxidative aging. The highest values of $S_{\mathrm{UV}}$ were observed for the vulcanizates containing HmiTFSI and HdmiTFSI, which were 0.58 and 0.61 , respectively. These ILs provided the best protection for SBR against UV aging.

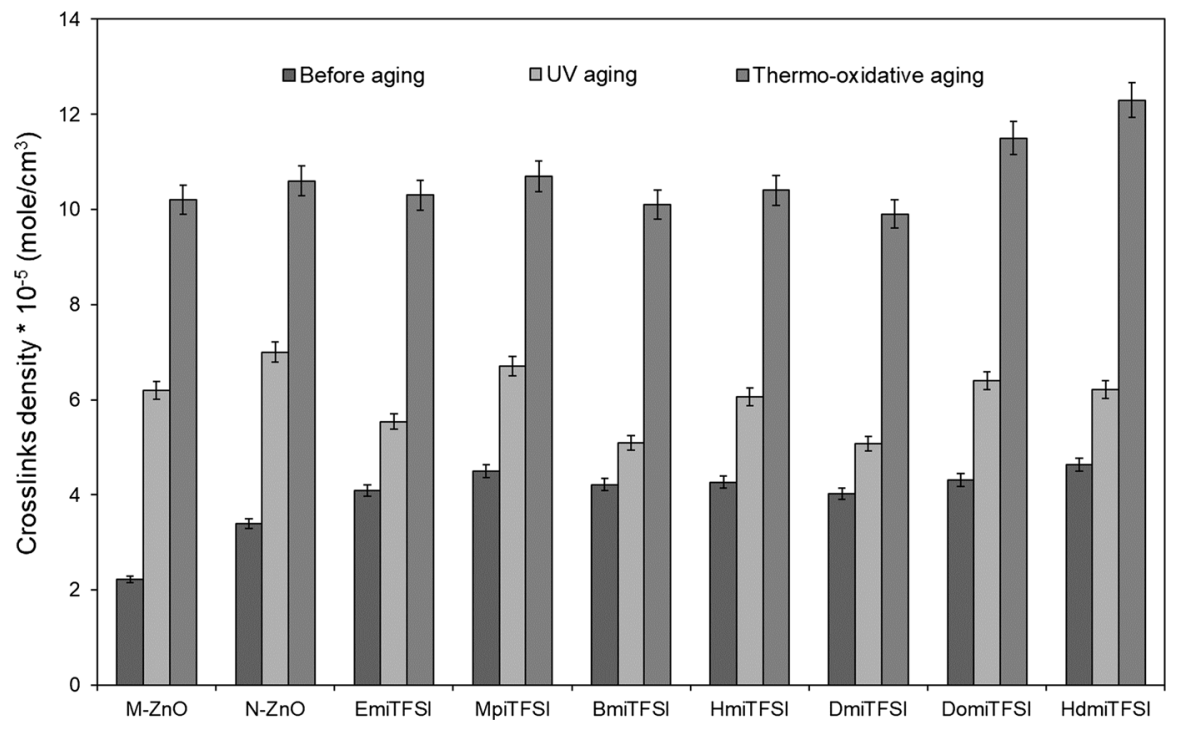

Fig. 7 Crosslink densities of SBR vulcanizates after aging 


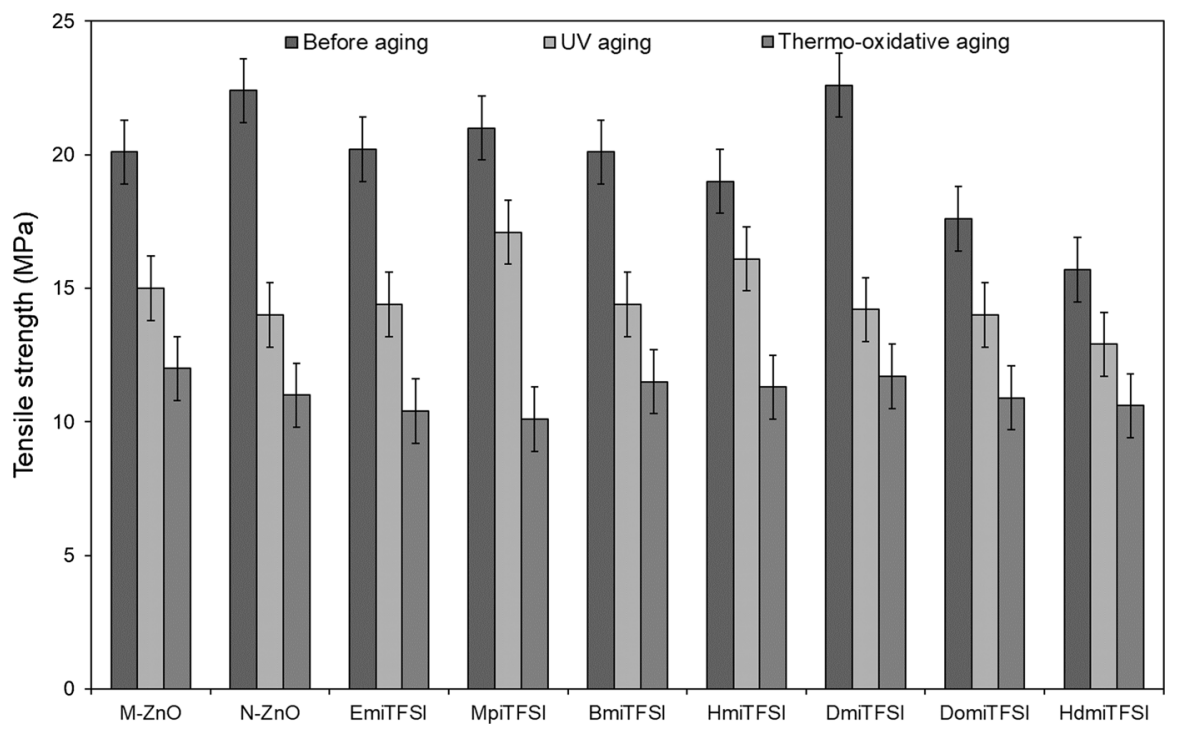

Fig. 8 Tensile strengths of SBR vulcanizates after aging

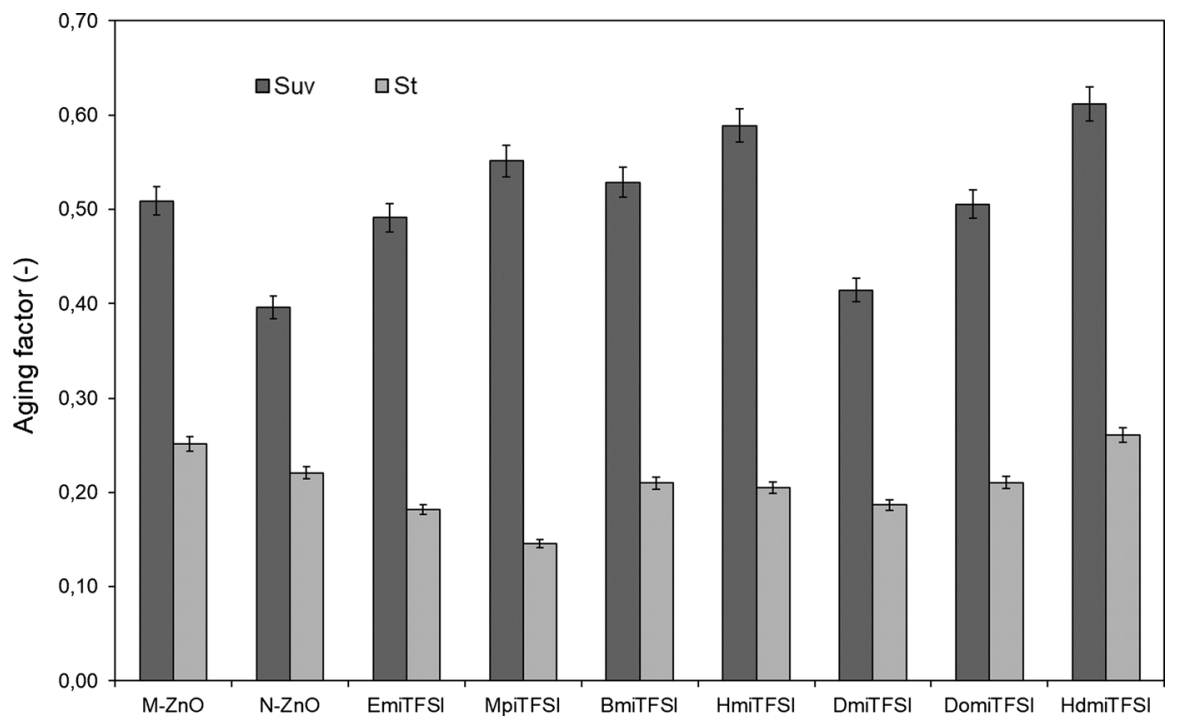

Fig. 9 UV and thermo-oxidative aging factors for SBR vulcanizates

\section{Conclusions}

Alkylimidazolium salts with TFSI anion considerably improved the degree of dispersion of curatives and carbon black particles in SBR. It can be concluded that ILs reduced the intermolecular interactions between particles of carbon black and reduced their tendency for agglomeration in the elastomer. 
Applying $\mathrm{N}-\mathrm{ZnO}$ allowed for a reduction in the amount of zinc ions by $60 \%$ compared to commonly used $\mathrm{M}-\mathrm{ZnO}$. ILs resulted in a shortened optimal vulcanization time and reduced the onset vulcanization temperature by $10-15{ }^{\circ} \mathrm{C}$ compared to $\mathrm{N}-\mathrm{ZnO}$ and by $20-25{ }^{\circ} \mathrm{C}$ when compared with $\mathrm{M}-\mathrm{ZnO}$ containing rubber compound. This is very important from a technological point of view. A considerable increase in the crosslink density of vulcanizates was also observed. Despite the reduced amount of zinc oxide, SBR composites containing most ILs exhibited tensile strengths comparable to the standard vulcanizate crosslinked with the microsized activator. The positive effect of ILs on the vulcanization kinetics and crosslink densities of the vulcanizates results from the improved dispersion degree of curative particles in the elastomer, especially zinc oxide. This feature leads to better contact between the vulcanization activator particles and other components of the crosslinking system. Equally important is the catalytic action of ILs in the interfacial crosslinking reactions.

ILs did not increase the resistance of SBR to thermo-oxidative aging. Regarding the resistance of the vulcanizates to UV aging, some improvement was achieved for HmiTFSI and HdmiTFSI.

Acknowledgements The authors wish to acknowledge the National Centre for Research and Development (Poland) for supporting this research (Project number LIDER/19/108/L-3/11/NCBR/2012).

Open Access This article is distributed under the terms of the Creative Commons Attribution 4.0 International License (http://creativecommons.org/licenses/by/4.0/), which permits unrestricted use, distribution, and reproduction in any medium, provided you give appropriate credit to the original author(s) and the source, provide a link to the Creative Commons license, and indicate if changes were made.

\section{References}

1. Lu J, Yan F, Texter J (2009) Advanced applications of ionic liquids in polymer science. Progr Polym Sci 34:431. https://doi.org/10.1016/j.progpolymsci.2008.12.001

2. Krossing I, Slattery JM, Daguenet C, Dyson PJ, Oleinikova A, Weingärtner H (2006) Why are ionic liquids liquid? A simple explanation based on lattice and solvation energies. J Am Chem Soc 128:13427-13434. https://doi.org/10.1021/ja073579a

3. El Seoud OA, Koschella A, Fidale LC, Dorn S, Heinze T (2007) Applications of ionic liquids in carbohydrate chemistry: a window of opportunities. Biomacromol 8:2629-2647. https://doi.org/10. 1021/bm070062i

4. Wasserscheid P, Keim W (2000) Ionic liquids-new "solutions" for transition metal catalysis. Ang Chem Int Ed 39:3772-3789. https://doi.org/10.1002/1521-3773(20001103)39:21<3772::aidanie $3772>3.0 . \operatorname{co} ; 2-5$

5. Hallet JP, Welton T (2011) Room-temperature ionic liquids: solvents for synthesis and catalysis. Chem Rev 111:3508-3576. https://doi.org/10.1021/cr1003248

6. Goujon LJ, Khaldi A, Maziz A, Plesse C, Nguyen GTM, Aubert P-H, Vidal F, Chevrot C, Teyssié D (2011) Flexible solid polymer electrolytes based on nitrile butadiene rubber/poly(ethylene oxide) interpenetrating polymer networks containing either LiTFSI or EMITFSI. Macromolecules 44:9683-9691. https://doi.org/10.1021/ma201662h

7. Rogers RD, Seddon KR (2003) Ionic liquids-solvents of the future? Science 302:792-793. https://doi. org/10.1126/science.1090313

8. Wasserscheid P, Welton T (2008) Ionic Liquids in Synthesis. Wiley-VCH, New York 
9. Shaplov AS, Ponkratov DO, Vlasov PS, Lozinskaya EI, Malyshkina IA, Vidal F, Aubert P-H, Armand M, Vygodskii YS (2014) Solid-state electrolytes based on ionic network polymers. Polym Sci Ser B 56:164-177. https://doi.org/10.1134/S1560090414020134

10. Cho M, Seo H, Na J, Choi H, Koo J, Lee Y (2007) High ionic conductivity and mechanical strength of solid polymer electrolytes based on NBR/ionic liquid and its application to an electrochemical actuator. Sens Actuators B 128:70-74. https://doi.org/10.1016/j.snb.2007.05.032

11. Lei YD, Tang ZH, Guo BC, Zhu LX, Jia DM (2010) Synthesis of novel functional liquid and its application as a modifier in SBR/silica composites. eXPRESS Polym Lett 4:692-703. https://doi.org/ 10.3144/expresspolymlett.2010.84

12. Subramaniam K, Das A, Heinrich G (2011) Development of conducting polychloroprene rubber using imidazolium based ionic liquid modified multi-walled carbon nanotubes. Compos Sci Technol 71:1441-1449. https://doi.org/10.1016/j.compscitech.2011.05.018

13. Kreyenschulte H, Richter S, Götze T, Fischer D, Steinhauser D, Klüppel M, Heinrich G (2012) Interaction of 1-allyl-3-methyl-imidazolium chloride and carbon black and its influence on carbon black filled rubbers. Carbon 50:3649-3658. https://doi.org/10.1016/j.carbon.2012.03.037

14. Guo BC, Chen F, Lei YD, Liu XL, Wan JJ, Jia DM (2009) Styrene-butadiene rubber/halloysite nanotubes nanocomposites modified by sorbic acid. Appl Surf Sci 255:7329-7336. https://doi.org/10. 1016/j.apsusc.2009.03.092

15. Byrne C, McNally T (2007) Ionic liquid modification of layered silicates for enhanced thermal stability. Macromol Rapid Comm 28:780-784. https://doi.org/10.1002/marc.200600754

16. Steinhauser D, Subramanian K, Das A, Heinrich G, Klüppel M (2012) Influence of ionic liquids on the dielectric relaxation behavior of CNT based elastomer nanocomposites. eXPRESS Polym Lett 6:927-936. https://doi.org/10.3144/expresspolymlett.2012.98

17. Das A, Stöckelhuber KW, Jurk R, Fritzsche J, Klüppel M, Heinrich G (2009) Coupling activity of ionic liquids between diene elastomers and multi-walled carbon nanotubes. Carbon 47:3313-3321. https://doi.org/10.1016/j.carbon.2009.07.052

18. Le HH, Hait S, Das A, Wießner E, Stöckelhuber KW, Böhme F, Reuter U, Naskar K, Heinrich G, Radusch H-J (2017) Self-healing properties of carbon nanotube filled natural rubber/bromobutyl rubber blends. eXPRESS Polym Lett 11:230-242. https://doi.org/10.3144/expresspolymlett.2017.24

19. Tang Z, Huang J, Wu X, Guo B, Zhang L, Liu F (2015) Interface engineering toward promoting silanization by ionic liquid for high-performance rubber/silica composites. Ind Eng Chem Res 54:10747-10756. https://doi.org/10.1021/acs.iecr.5b03146

20. Behera PK, Usha KM, Guchhait PK, Jehnichen D, Das A, Voit B, Singha NK (2016) A novel ionomeric polyurethane elastomer based on ionic liquid as crosslinker. RSC Adv 6:99404-99413. https://doi.org/10.1039/C6RA21650

21. Yuan Ch, Guo J, Sia Z, Yan F (2015) Polymerization in ionic liquid-based microemulsions. Polym Chem 6:4059-4066. https://doi.org/10.1039/C5PY00423C

22. Vijayaraghavan R, MacFarlane DR (2004) Living cationic polymerization of styrene in an ionic liquid. Chem Commun 6:700-701. https://doi.org/10.1039/B315100J

23. Sarbu T, Matyjaszewski K (2001) ATRP of methyl methacrylate in the presence of ionic liquids with ferrous and cuprous anions. Macromol Chem Phys 202:3379-3391. https://doi.org/10.1002/15213935(20011101)202:17<3379::aid-macp3379>3.0.co;2-3

24. Sun N, Rahman M, Qin Y, Maxim ML, Rodriguez H, Rogers RD (2009) Complete dissolution and partial delignification of wood in the ionic liquid 1-ethyl-3-methylimidazolium acetate. Green Chem 11:646-655. https://doi.org/10.1039/B822702K

25. Phillips DM, Drummy LF, Conrady DG, Fox DM, Naik RR, Stone MO, Trulove PC, De Long HC, Mantz RA (2004) Dissolution and regeneration of bombyx mori silk fibroin using ionic liquids. J Am Chem Soc 126:14350-14351. https://doi.org/10.1021/ja046079f

26. Biswas A, Shogren RL, Stevenson DG, Willett JL, Bhownik PK (2006) Ionic liquids as solvents for biopolymers: acylation of starch and zein protein. Carbohydr Polym 66:546-550. https://doi.org/10. 1016/j.carbpol.2006.04.005

27. Petrovic ZS, Javni I, Divjakovic V (1998) Structure and physical properties of segmented polyurethane elastomers containing chemical crosslinks in the hard segment. J Polym Sci Part B Polym Phys 36:221-235. https://doi.org/10.1002/(sici)1099-0488(19980130)36:2<221::aid-polb3>3.0.co;2$\mathrm{u}$

28. Lu X, Huang J, He G, Yang L, Zhang N, Zhao Y, Qu J (2013) Preparation and characterization of cross-linked poly(butylene succinate) by multifunctional toluene diisocyanate-trimethylolpropane polyurethane prepolymer. Ind Eng Chem Res 52:13677-13684. https://doi.org/10.1021/ie4020342 
29. Nieuwenhuizen PJ (2001) Zinc accelerator complexes.: versatile homogeneous catalysts in sulfur vulcanization. Appl Catal A Gen 207:55-68. https://doi.org/10.1016/S0926-860X(00)00613-X

30. Flory PJ, Rehner J (1943) Statistical mechanics of cross-linked polymer networks II Swelling. J Chem Phys 11:521-526. https://doi.org/10.1063/1.1723792

31. Furuta I, Kimura S, Iwama M (1999) Physical constants of rubbery polymers. In: Brandrup J, Immergut EH, Grulke EA (eds) Polymer Hand Book, 4th edn. Wiley, New York

32. Masek A, Zaborski M, Kosmalska A (2011) Derivatives of flavonoides as anti-ageing substances in elastomers. CR Chim 14:483-488. https://doi.org/10.1016/j.crci.2011.01.001

33. Becheri A, Dürr M, Lo Nostro P, Baglioni P (2008) Synthesis and characterization of zinc oxide nanoparticles: application to textiles as UV-absorbers. J Nanopart Res 10:679-689. https://doi.org/10. 1007/s11051-007-9318-3 